\title{
Water Management: A Solution to Water Scarcity in Pakistan
}

\author{
Dr. Bashir Ahmad
}

\begin{abstract}
With the increase in population of our country and changing geo-political landscape, the available water resources are fast depleting. We also understand that without water, there can be no life as we see in this physical world. The solution lies in judicious usage of water and realization to preserve, which ultimately leads to superior management of this essential resource. This paper addresses the issues pertaining to water required for agriculture, drinking as well as for other purposes. The measures recommended for preservation of irrigation water include cost effective maintenance of water channels under an integrated mechanism of public-private partnership and ownership through community participation. Similarly to resolve the issues related to drinking and general purpose water, a distinction between the two categories has been proposed for putting in practice under an integrated approach. For the purpose of enhancing storage capacity, instead of fighting on the construction of much awaited mega dams, the paper suggests construction of small dams and run of the water channels auto-spillover bunds. These measures, apart from being cost effective (i.e. affordable) shall have no political controversies. The concept is storage of water through spread over river beds and storage sites. The paper also suggests measures for creating awareness among our people to make judicious use of water.
\end{abstract}

Keywords: Water management, population, public-private partnership, storage capacity, small dams.

\section{Introduction}

\section{Why We Need Water Management?}

"And among His signs is that He shows you the lightening, for fear and for hope, and He sends down water (rain) from the sky, and therewith revives the earth after its death. Verily, in that are indeed signs for a people who understand."

$$
\text { Al Qur'an }
$$

(Surah Ar-Rum, Verse 24)

Water is a natural commodity which sustains life on our planet, may it be in the shape of plants, animals or human beings. In fact without water there can be no life as we see in this physical world. At the same time we find that water does not exist in unlimited quantity, rather its storage has certain limits within which it recycles under a natural system. The living beings and plants require certain quantity of water, if deficiency

Dr. Bashir Ahmad, Principal (Designate) Gwadar Institute of Technology, Baral Colony, Mangla Cantonment, Punjab, bashirahmad127@yahoo.com

Journal of Independent Studies and Research - MSSE

Volume 9

Number 2

July $2011 \mid 111$ 
occurs beyond the desired limits, the life is threatened. This simply implies "No water No life". Allah has created every living being on the earth surface out of water, as $\mathrm{He}$ narrates it at number of places in the Holy Quran.the islam's holy book also in Surah Al Baqar, Verse no 164 and Surah Qamar Verse no 11 refers to the issue of water translation of whih is given below respectively:

"Verily in the creation of heavens and the earth, and in the alternation of night and day, and the ships which sail through the sea with that which is of use to mankind, and the water (rain) which Allah sends down from the sky and makes the earth alive therewith after its death and moving (living) creatures of all kinds that He has scattered therein, and in the veering of winds and clouds which are held between the sky and the earth, are indeed Ayahs (proofs, evidences, signs) for people of understanding."

"So We opened the gates of the heaven with water pouring forth."

With the increase in population and ongoing rapid industrialization - urbanization, consumption of water has increased manifold. This has resulted into a situation of water scarcity, leading to water crisis, particularly in countries like Pakistan. Here I use the term 'water crisis' to refer to the availability of water relative to our requirements. Water here means the 'usable water' not its overall availability as it exist on our planet like the sea water which cannot be used for living beings till the time it is processed to make it usable. As referred above, our Earth has a finite supply of fresh water, stored in aquifers, some quantity as surface waters and certainly some in the atmosphere (greenfacts.org, 2010).

Where deficiency of water may slowly lead to economic crisis and consequently elimination of living beings, its availability - flow in excess to our capacity of storage and drainage into the sea becomes disastrous for the living beings like we see the situation of floods in Pakistan in the past and the one occurred in August 2010. The recent floods just washed away the human settlements - large number of our towns, cities and villages apart from the destruction of crops at large scale and deaths of human beings as well as animals. It has incurred colossal loss to our economy which may take decades to recover. Therefore it is catastrophic in either way (i.e. the deficiency of water as well as its excess beyond certain limits). At the same time, in its polluted form, water leads to the outbreak of numerous diseases and consequently large scale deaths. According to a survey, at any given time, almost half of the hospital beds are occupied of patients suffering from waterborne diseases worldwide. In that, 88 per cent of all waterborne diseases are caused by unsafe drinking water which also results into inadequate sanitation and poor standard of hygiene (CNN, 2007).

When you have meagre resources and increasing demands, solution has to be sought in the effective management of available means. Here management of water implies that every living being gets the due share to survive. Management of water is to reduce its wastage to the bare minimum. At the same time, management also implies storage of water and its effective regulation through various channels for controlled and useful flows. It is the imprudent actions of humans that result into water scarcity and devastation of droughts. United Nations report on water issues focuses on governance as the core 
of water crisis, maintaining "There is enough water for everyone and water insufficiency is due to mismanagement, corruption, lack of appropriate institutions, bureaucratic inertia and shortage of investment in both human capacity and physical infrastructure" (The United Nations World Water Development Report, 2006).

\section{Availability of Water and Our Needs}

Out of the total available water on our planet, $97 \%$ is saltish, thus not suitable for human beings, animals as well as plants. Only $3 \%$ freshwater available is useful for the living beings. Out of this $3 \%$, almost $66 \%$ is frozen in glaciers and $33 \%$ is available on the surface, underground and some part in the air. Nature has its own system of recharging these resources through precipitation. The storage of fresh water depends upon the capacity of lakes, wetlands and artificial reservoirs. Seepage, run off rivers into the sea and evaporation incur loss of water. Therefore the quantity of water available at a given time is dependent upon the storage capacity of a country in the shape of reservoirs (US Geological Survey, 2010). Desalination is an artificial process of converting saline water into its usable form which is expensive compared to most of the alternative sources of water available. In Pakistan, it is in its preliminary stage where Pakistan Navy has developed limited quantity plants for desalination.

Looking at the issue from agricultural point of view, which is the backbone of national economies in most of the developing countries, Pakistan has a total geographical area of 196 million acres out of which 77.1 million acres is suitable for agriculture. A total of 54.5 million acres (71 per cent) out of the total agriculturable land is already cultivated either by irrigation or through rain. The remaining 22.6 million acres of land which constitutes 29 per cent of the total area suitable for agriculture can become productive if water is made available for irrigation (Economic Review, 2002). It means that a little less than one third of the agricultural potential of Pakistan remains untapped because of non-development of water resources and associated infrastructure as well as its poor management.

Pakistan's water needs can be categorised as those for agriculture (elaborated above), industrial and domestic uses. In Pakistan's predominantly agrarian economy, irrigation consumes about $97 \%$ of the total quantity available and contributes $25 \%$ (almost) in our GDP. This means that out of total available potable water, $3 \%$ is available for industrial and domestic use. Based on the data of year 2009 /2010 (WAPDA, Study Paper, 2009), total water needs of Pakistan and its availability are as given below:

$\begin{array}{llll}- & \text { Water available } & - & \text { 125.56 MAF } \\ \text { - } & \text { Water required } & - & \text { 164.48 MAF } \\ \text { - Shortage } & - & 38.92 \mathrm{MAF}(31 \%)\end{array}$

The irrigation system of Pakistan is one of the largest in the world serving 36 million acres of cultivated land. The irrigation network is maintained through three main storage reservoirs / dams, eighty small dams, nineteen barrages, twelve link canals and forty five command canals (Ministry of Planning and Development, 2005). This network is to regulate $97 \%$ of the total fresh water solely for irrigation purpose. The left-over $3 \%$ is used for domestic and industrial purpose with mutually interchanging percentages.

Journal of Independent Studies and Research - MSSE

Volume 9

Number 2

July $2011 \mid 113$ 
Whereas the industrial sector meets its requirement adequately, clean drinking water is not available to the entire population of Pakistan. The drinkable water is not available in greater part of Sind, Baluchistan and southern Punjab. Therefore the population of these two provinces in particular and some other parts of the country in general is dependent on rain water accumulated in natural and manmade ponds.

The problem of drinkable water is compounded in cities where population has grown out of proportion to the availability of water like Karachi, Lahore, Faisalabad and Rawalpindi / Islamabad. According to (Planning Commission, 2010) various sectors, the water requirements of Pakistan are as given below:

- Irrigation

- Domestic sector uses

- Industrial use

$\left.\begin{array}{cc}- & \text { 159.54 MAF } \\ - & \text { 3.82 MAF } \\ - & \text { 1.1 MAF }\end{array}\right] \begin{aligned} & \text { likely to increase to } \\ & \text { 12.1 MAF by } 2025\end{aligned}$

With the increase in population and consequently the requirement of water, shortage is going to increase in years to come. Since 1951 (Ministry of Planning and Development, 2005), per capita availability of water is decreasing as shown below:

\begin{tabular}{|ccc|}
\hline Year & Population (in Millions) & Water Availability (in Cubia Meter) \\
1951 & 34 & 5260 \\
1961 & 46 & 3950 \\
1971 & 65 & 2700 \\
1981 & 84 & 2100 \\
1991 & 115 & 1600 \\
2000 & 148 & 1200 \\
2001 & 172 & 1078 \\
2013 & 207 & 850 \\
2025 & 221 & 659 \\
\hline
\end{tabular}

As per United Nations Water Needs Report (www.unwater.org), 1000 cubic meter per capita availability of water is the threshold. Therefore by international standards, in 1991, Pakistan at 1600 cubic meter per capita availability of water was 'a water scarce country'. Now at about 1000 cubic meter per capita, we are a water stress country (Pakistan Statistical Book, 2007). The situation is going to further deteriorate in years to come as shown in the data tabulated above. This implies that we need to find a solution to the problem at priority.

\section{Analysis - Magnitude of the Issue and Way Forward Shortfalls of the Irrigation System / Network and Corrective Measures}

The present irrigation network of Pakistan was developed by the British prior to creation of Pakistan (baring few irrigation canals which were constructed in 1960s). Thereafter any addition to irrigation network has been a rare occasion. As far as link canals are concerned, these have been constructed in 1960s under the Indus Basin Treaty with India. Some of these canals, especially the irrigation ones, were constructed above the earth surface with raised banks; hence they developed seepage and with the passage of time resulted into rising of water levels - leading to water logging and salinity. The 
adverse effects were loss of water due to seepage and spoilage of cultivable land as a result of water logging and salinity. The solution lied in below or at the level of earth surface water flowing canals or their brick lining. At this point in time, bringing all these canals at the level of earth surface or below earth surface is a gigantic work which may not be economically and technically feasible. We need to look for alternate means to resolve these issues. However, the lesson is that we should go for below the earth surface level canals in future as they are technically feasible. At the same time, to manage the problems of water wastages through seepage and resultantly the water logging and salinity, we need to undertake certain concrete measures, some of which are as listed below:

- Regular maintenance of canals and other water channels to maintain unobstructed water flow is the first step to reduce seepage. What happens is that with the passage of time, sedimentation results into silt pockets which accumulate more and more silt and create such mounds. These mounds of silt grow in size with the growing of grass and bushes upon them and become major sources of obstruction in the flow of water. The accumulated water around the silt mounds exerts pressure sideways and results into seepage. Their regular maintenance would ensure uninterrupted water flow, hence less seepage and consequently the wastage.

- Construction of roads and tracks on both sides of the water channels and their permanent use is another way of reducing seepage. With strong and level embankments on either side of the water channels, the construction of roads / tracks is easy apart from its scenic beauty. Their permanent use would ensure continuous pressing of the earth surface thereby reducing seepage of water to a great extent.

- $\quad$ Providing an alternate source of water to the grazing animals is another very important step towards protecting the banks of water channels. The grazing animals cause enormous damage to the water channels in terms of their obliteration and consequently outflows of water. Animals like buffalos, particularly when those are in large numbers damage the banks of irrigation network and at the same time obstruct water flow when they sit inside the water channels. This results into erosion of banks, silting of the beds and ultimately wastage of water in the form of outflows and seepage. Construction of ponds for the grazing animals at appropriate places adjacent to the water channels would reduce the water wastage as well as damage to the banks of canals etcetera. These ponds would have controlled links to the canals to allow fresh water to flow inside when required.

- $\quad$ Selective brick linings, particularly in areas which have been affected by rising water levels leading to water logging and salinity is a cure to revive the sick land. The selective brick linings will stop the further seepage. The already effected land can be cured through pumping out of the seepage water and removal of salinity by various means like suitable plantation, use of curing fertilizers and covering the surface with fresh earth. Brick 
lining reduces the seepage by blocking the porous surface and facilitating free flow of water which reduces pressure on the side banks.

\section{A Viable Way Forward - How to do and who should do?}

Implementation of the corrective measures made above requires a detailed, long-term planning and execution strategy through a phased programme. In my views there are three ways to do it.

1) planning and its execution through government machinery,

2) leaving it to the private sector where users to plan and undertake the work and 3) thirdly a combination of the two.

The government machinery being sluggish and reputed as corrupt may not be able to develop consensus, gather necessary funds and undertake the work as envisaged. The private sector is devoid of leadership, historically dependent on official way of implementation, therefore will not be able to develop mutual understandings and vision to undertake such a gigantic work. Therefore, the solution lies in combination of public and private sectors - a joint approach for planning and execution of water vision for our future generations. Salient aspects of this public - private integrated approach (PPIA) are as given below:

- $\quad$ Government to constitute a body of experts and administers to undertake planning and developing resources to finance the envisaged 'Water Vision'. It should be constituted at the federal as well as provincial levels, to be known as Federal Water Management Authority (FWMA) and Provincial Water Management Authority (PWMA) respectively.

- $\quad$ FWMA be mandated to plan management - conservation and regulation of water of the rivers. It should include building storage capacity in the shape of reservoirs and dams, regulating water in the rivers through building and managing barrages and link canals, equitable distribution of water to all the stakeholders and maintaining river beds to sustain requisite flow capacity in view of extra / unusual rains.

- $\quad$ PWMA be mandated to manage the water in irrigation canals within the jurisdiction of their respective provincial boundaries. PWMA to deal with the canals up to their tail ends and also build seasonal canals as well as their maintenance to drain out the excess water - a safety valve to deal with an unforeseen / eventuality.

- Maintenance of water channels from the water connection point at the canal ends up to the field should be the responsibility of respective district administration / governments' to be known as DWMA (District Water Management Authority). 
- $\quad$ Finances for the maintenance of all water courses / channels to be met from the users (i.e. farmers). The water management authorities at all levels i.e. federal, provincial and district should have representatives from the users. Execution of work, especially at district and below levels should be undertaken through user's participation like town and village committees. At the federal and provincial levels, we already have public representatives in the shape of members of National and Provincial assemblies.

- $\quad$ The bottom line philosophy is to inculcate sense of belonging / ownership to make every user realize that every drop of water matters for life, the loss of which is like his personal loss. That is possible only when one pays the price for every drop of water. Otherwise it has become our second nature to expect everything from the government to do, not realising that governments run on the public money. The joint and collaborated efforts can make our system better through self and public accountability.

\section{Drinking Water Problems and their Resolution Issues / Shortfalls of the System}

There are two separate areas of our water supply concerns (i.e. urban and rural areas). Both have their own distinct characteristics and dynamics. Similarly with respect to the availability of water in urban and rural areas again there are two issues; non availability of water at the consumer end and secondly availability of water but in polluted form. Both these problems need separate approaches for a viable resolve which have been dealt with accordingly in the ensuing paragraphs:

\section{Water Management Problems of Our Urban Areas}

- $\quad$ Our urban areas have grown out of proportion to the availability of services, especially the supply of fresh water. Even within the cosmopolitan cities like Karachi, Lahore, Islamabad etcetera there are certain pockets which are over populated than adjacent colonies. To manage water supply to such a large population, all put together at one place, is a gigantic task which needs enormous resources and superior management and administration. Their maintenance is even difficult through heavy traffic and population, especially in narrow streets and apartments.

- $\quad$ Secondly, we do not have distinction between drinking water and the water required for gardening / vegetation. Water supply system is the same from where consumers take water for drinking, bathing / washing as well as for gardening etcetera. Whereas water requirements of both the categories are different, but our supply system is the same. In this way, we waste precious drinkable water for washing and vegetation etcetera. 
- $\quad$ Furthermore to the wastage of fresh drinkable water, we do not have the accountability mechanism of water consumption. With negligible water tax, our consumer has unlimited supply of water at his disposal according to his status / approach to the concerned departments. In the same colony / street, one may find people without water even for drinking purpose and certain privileged ones having overflowing water in excess to their lawns and gardens.

\section{Water Management Problems of Our Rural Areas}

- $\quad$ Our Rural Areas have also expanded over larger areas with new settlements, particularly of those who migrate from village to village in search of livelihood. Wherever they find a suitable place, get settled, may it the river bed or under a bridge. Thereafter these settlements start growing in size and turn into villages and towns. Most of the settlements and villages washed away in the recent floods have been those constructed in the river beds and low lying areas. There are basically two issues with the availability of water in rural areas. One is the increase in population exerting more demands of water supplies and shrinking water sources closer to populated areas.

- $\quad$ Secondly, over pumping has lowered the water table in certain areas and now it is getting deeper and deeper, making it almost impossible to get more water even with better technologies. The water available on the surface of the earth is either the rain water accumulated in natural and manmade ponds or river water which flows in various canals. None is drinkable till the time it is cleaned and made usable.

\section{Resolving the Issues - How to do and who should do?}

In order to resolve these issues, may it be in the domain of rural or urban areas, water management is required to be understood and applied in letter and spirit. Since urban and rural areas have their distinct problems so their resolution requires separate approaches as well.

\section{Resolving Urban Areas' Water Problems}

- $\quad$ The bigger cities like Karachi, Lahore, Faisalabad, Hyderabad, Peshawar and Rawalpindi - Islamabad have become unmanageable under the management cum administration of a district. Since at this stage it is not possible to undo their varied size, we need to do two things. Firstly stop their further growth and organize the existing population to make it manageable. Secondly divide these cities into distinct manageable units which should be autonomous and accountable for the availability of essential services including water. 
- Management of water should be devolved to the level of district government / administration under self sustenance mechanism. We would need to get out of the mindset of free water supply. It should be a community based transparent water supply system where one has to pay for the quantity of water he desires to consume. The culture of free supply of water even to the government departments should be stopped forthwith. Rather all government offices be authorised certain scales for which the money should actually be paid to the Districts' Domestic and Industrial Water Management Authority (DD\&IWMA). The system would work effectively only when there is no discretion and no free supply of water.

- DD\&IWMA would offer two types of connections to the consumer i.e. one, water connection for drinking, cooking, bathing, washing and second for gardening, vegetation, cleaning the toilets etcetera. Both the water supply connections would have different rates for payment of water service charges. The consumer would be billed at the end of every month according to his usage of water.

- $\quad$ At the same time we would need to improve the water supply system including repair of the water supply lines to reduce wastage. Improvement of services through an efficient management mechanism would encourage the consumers to pay for water services.

\section{Resolving Rural Areas' Water Problems}

- In rural areas, the situation is slightly different. In rural areas of the Punjab baring some parts of southern Punjab and Khyber Pakhtun Khwa sufficient quantity of underground drinking water is available. Therefore, the problem is how to extract the water and subsequently make its supply to the consumer's end. Its implication is the requirements of pumping motors and water supply lines. In terms of expenditures, it is not an expensive issue. It requires only the division of areas into manageable units and provision of underground fresh water to the consumers. In order to conserve the underground resource of fresh water, its pumping by the individual consumers be stopped. It should rather be organised on area basis under the community based government mechanism as that of urban areas.

- We have a more pronounced problem of water scarcity in most of the rural areas of Sind and Balochistan, where underground drinkable water is seldom available. In parts of Sind, especially adjoining areas of Arabian Sea, the underground water is available but it is brackish. In its desert part, the underground drinkable water is not available at the extractable depths. In both the cases canal / rain water is required to be stored in ponds, clean it to make it drinkable and then supply to the population scattered over larger areas in the form of hutments and villages. 
- In Balochistan, the situation is different. There the groundwater is mostly not available therefore majority of the population is dependent on natural springs and underground water tunnels known as Karez. The Karez is an ancient type of water supply system developed in earlier times and still in use in arid regions of the world. In Karez, underground water sources are channelled downhill through a series of tunnels to the places where it is needed. From here the water is either taken to the fields and villages through vertical shafts which are sunk underground or it is drawn out at the foot of the hill where it had been gathered. In order to keep the underground channels unclogged, two men and a draught animal work as a team where one man is lowered down to clear the channel who fills the buckets with mud which is then taken out by the animal (Dr. M Fazle, 1995). This is an age old system, which is a human effort but intensive and difficult in transportation of water. Like other parts of the country, people of Balochistan also deserve drinking water through a well laid out water supply system.

- In both the cases, the solution lies in developing the water sources and handing them over to the community based water management mechanism / administration to maintain it on self sustaining principles. In underdeveloped areas like most part of Balochistan, the water supply has to be subsidised to make it affordable to the population. The solution is not cost prohibitive, it is affordable and requires only management. However, it should not be free in any case otherwise no supply system can sustain for longer.

\section{Enhancing Storage Capacity}

In order to have sustained and continuous supply of water for agriculture, industrial as well as domestic uses, it is necessary to enhance our storage capacity, may it be in any shape i.e. dams, ponds, river beds etcetera. Some of the cost is affordable / sustainable and less controversial options are as given in the succeeding paragraphs:

- Construction of New Mega Dams has been contentious issue over the last many years. This is the reason that after late 1960s, there has been no worthwhile breakthrough in construction of new mega dams. At the same time, the bigger dams have become cost prohibitive, especially initial investment and large scale rehabilitation / resettlements required. The solution lies in having smaller dams in suitable areas all over the country. Even the sites already planned for mega dams like Kala Bagh may require to be redesigned for lesser capacity dams so as to avoid large scale resettlement. Earlier we had to have bigger dams to provide more gradient to water falls for efficient running of the turbines to produce more electricity. Now with the improved technology, this is not required; the turbines can be operated even at run of the river gradients. Modern technologies have solved the problem by introducing run of the river hydro electric power projects which are in place in most of the countries, being constructed in Pakistan as well (one such project is under construction at Bong, near Kharry Sharif, in Mirpur, Azad Jammu and Kashmir). 
- $\quad$ River Bed Transit Storage capacity can be enhance by selecting suitable sites at appropriate distances in our existing rivers, where less effort is required to raise the banks and create water storage capacity. The main idea behind is to hold some water in the river bed by constructing auto overflowing spillways according to the capacity of its banks. In this way we would be able to hold water at certain levels and thereafter it would automatically flow over the spillways. Its benefits would be; one, all the times, some water shall always be available in the river for grazing animals as well as for vegetation / plantation. Secondly, during dry spells, the water may be released to meet our requirements downstream. Thirdly, anticipating (forecasted) rains, the storage ponds may be emptied to hold upcoming more water and regulate it as required. This means that in flood like situations we will have all our rivers holding water as per their designed capacitates of banks and spillways. With this storage, we would be able to divert excess water to other areas through safety valves canals, especially designed and constructed for this purpose.

- $\quad$ Construction of Safety Valves Canals provides a solution to the flood waters in monsoons when water become surplus and beyond the capacity of our rivers / barrages. Safety valve canals are suggested to be constructed in relation with the construction of transit storage spillways as explained above and existing barrages / regulators. In case of excess water / flood like situations, the safety valve canals would lead water to the dry river beds like Sutlej and Ravi which remain dry most of the times even when there is high flood situation in other three rivers. Secondly, these canals would also take the excess water to dry / desert parts of the country like Southern Punjab, some parts of Sind and Balochistan. The idea behind is that why not to take this excess water to the dry / desert areas of the country where there is always shortage of water instead of throwing it into the sea. Unfortunately in the recent floods, where some parts of the country, especially in Sind and Balochistan were worst hit by the floods, the other parts were facing acute shortage of water. This happened in Sind on 5 September 2010, when Dadu and Thatta were under water and three farmers set themselves on fire against non supply of irrigation water in Sukkur (The Daily Jang, 2010). The safety valve canals would not only control the flood waters, also provide life to the barren and water scarcity parts of the country.

Mass Public Awareness about Water Management is essentially required to take the people along with the campaign at the government levels. The most effective instruments are television and radio for the general - comparatively less educated population and print medium focussing on the educated segment of the society. Awareness and motivation at the national level is one aspect of the issue, the other segment of the campaign is equally important and that pertains to making the masses realize through their contribution / payment for the services, they avail / utilise. What has been observed in our mass public perception is that they become careful when they know that whatever 
one consumes, he would require paying for that, may it be a very small amount. Mere motivation does not work as free services do not convey severity of the issue.

Creating a Self Sustaining Water Sector is need of the hour. Water is an important natural commodity and unfortunately in Pakistan, it does not have its own resources to make any development. If we look at its consumption (i.e. relationship of demand of supply) we find that it is the most essential commodity. We need a water sector development strategy (WSDS) over a longer period of time - a "Water Vision", which needs resources. We would require creating a broad based water sector at all tiers of the government machinery and making it economically viable and sustainable. For that purpose there is a need to undertake constitutional reforms. We need water management mechanism as a joint venture of public and private sectors at the federal, provincial and district government levels, some of them have been explained in the earlier parts of this paper.

Controlled Pumpage of water is essentially required for sustained supply of water in areas where water level is going deeper and deeper due to unchecked pumping through powerful electric, diesel and petrol motors / engines. At the moment, there is no check on any individual to bore the earth and install tube wells. This has resulted into scarcity of water in certain areas due to overpumping, particularly in central Punjab. With better technology, the consumers are going deeper and deeper to extract water but soon a stage is approaching where it will remain no more possible to get any further water even with the more powerful motors/ pumps. Therefore it is necessary to maintain certain level of underground water imposing restriction on pumping of water for the purpose of irrigation etcetera, so that at least drinking water is available in such areas. At the same time, instead of individual water extraction, mostly in rural areas, we should resort to community based water supply schemes to conserve this fast depleting essential natural commodity.

Inequitable Distribution and Inefficient Use of water leads to socio - political disorder and unacceptable wastage of water respectively. This is particularly so in the case of irrigation water, where its inequitable / unjust distribution creates feelings of deprivation and dissatisfaction in certain segments of society and at the same time, its inefficient use adds to the wastage of water. There is a need to take stock of the whole situation and ensure equitable distribution amongst all water users. Secondly we need to educate our farmers for the efficient use of water in the light of modern technology utilising appropriate crop patterns and water management within the fields. Brick lining of water channels, which has already started in Punjab, would also reduce water wastage in greater quantities.

Desalination has to be seen against its cost. As new technological innovations continue to reduce the capital cost of desalination, more countries are building desalination plants to address their water crises (www.libraryindex.com). Leading countries excelling in this field are as under:

- Israel desalinizes water for a cost of 53 cents per cubic meter. With new technologies and developments in this field, the cost is going to decrease.

- $\quad$ Singapore desalinizes water for 49 cents per cubic meter and also treats sewerage with reverse osmosis for industrial and potable use. 
- $\quad$ China and India, the world's two most populous countries, are turning to desalination to meet some of their water needs.

- $\quad$ All Australian capital cities (except Darwin, Northern Territory and Hobart) are either in the process of building desalination plants, or are already using them. In late 2011, Melbourne will begin using Australia's largest Desalination Plant?the Wonthaggi desalination plant?to raise low reservoir levels.

- The largest desalination plant in the United States is the one at Tampa Bay, Florida, which began desalinizing 25 million gallons $\left(95000 \mathrm{~m}^{3}\right)$ of water per day in December 2007. In the United States, the cost of desalination is $\$ 3.06$ for 1,000 gallons, or 81 cents per cubic meter.

- The world's largest desalination plant is Jebel Ali Desalination Plant in the United Arab Emirates. It is a dual-purpose facility that uses multi-stage flash distillation and is capable of producing 300 million cubic meters of water per year. While desalinizing 1,000 gallons of water can cost as much as $\$ 3$, the same amount of bottled water costs $\$ 7,945$.

However, given the energy intensive nature of desalination, with associated economic and environmental costs, desalination is generally considered a last resort after water conservation. In view of the transportation charges to carry the water up till our coastal areas, we may have to make use of the desalination process at some point in time. It is therefore recommended that we get into the technological mind-set and get to know details for making some headway in this field as well.

\section{Conclusion}

We need efficient and integrated management of water in view of its increasing demands vis-a-vis depleting reserves. God has created this commodity according to the requirements of mankind. However without management, it is not sustainable. Our religion, Islam also teaches preserving this essential natural commodity. The Holy Prophet Muhammad (Peace be upon him) prohibited misuse of water even while making ablution for prayers, saying that the one who exceeds repetition of washing hands and feet more than three times is the one who exceeds the limits which is bad and not liked. 


\section{References}

Ali, Yusuf (1934), The Meaning of the Holy Qur'an, Lahore.

All About Water and Health, CNN, December 18, 2007.

Draft State of Environment Report (2005), Report compiled by Ministry of Planning and Development.

"Earth's Water Distribution". United States Geology Survey. http://ga.water.usgs.gov/edu/ waterdistribution.html. Retrieved 2010-08-19.

Overall Water Availability, Report by Ministry of Economic Affairs and Statics, Statics Division, Government of Pakistan, Pakistan Statistical Book (2007), p 1-15, http://www.statpak.gov.pk/depts/fbs/publications/yearbook2007/agriculture, retrieved August, 2010-08-19.

Pakistan Facing Acute Shortage of Water, Economic Review, July 1, 2002.

Pakistan's Vision of Water Resource Management, (2005), Report by Ministry of Planning and Development, Government of Pakistan.

Professor Dr Muhammad Fazle Karim Khan, Karachi University, Assistant Professor Muhammad Nawaz, Balochistan University, Karez Irrigation in Pakistan, Geo-Journal 37.1 (Kulwer Academic Publishers, September, (1995), available at www.inweh.unu.edu/drylands/docs, reference taken on November, 14, 2010 at 2200 hours.

Scientific Facts on Water: State of the Resource. Green Facts Website, http://www.greenfacts.org/en/water-resources/index.htm2. Retrieved 2010-08-06

Ten year Perspective Development Plan 2001 - 2011, Planning Commission, Government of Pakistan, http://www.statpak.gov.pk/depts, retrieved August, 2010-08-19.

The Daily Jhang, September 8, 2010.

The Global Dimensions of Water Governance: Nine reasons for global arrangements in order to cope with local problems. Value of Water Research Report Series No 20 UNESCO - IHE Institute for water education.

The Arid West - Where Water is Scarce - Desalination - a Growing Water Supply Source, Library Index, International Water Management Institute, World Water Supply and Demand: 1995 to 2025, retrieved from "http://en.wikipedia.org/wiki/water resources, updated August, 15, 2010.

Water Facts and Trends - UN-Water, www.unwater.org/downloads /Water_facts_and_ trends.pdf

Journal of Independent Studies and Research - MSSE

Volume $9 \quad$ Number 2

July $2011 \mid 124$ 
Water Availability Report 2010, prepared by WAPDA, Study Paper 2009 / 2010 (Not Published)

Water, A Shared Responsibility. The United Nations World Water Development Report 2, 2006. Information extracted from "http://en.wikipedia.org/wiki/Water_crisis 2010-08-06. 